\title{
A FOODBORNE OUTBREAK DUE TO CRYPTOSPORIDIUM PARVUM IN HELSINKI, NOVEMBER 2008
}

\author{
A Pönka (antti.ponka@hel.fi) ${ }^{1}$, H Kotilainen², R Rimhanen-Finne ${ }^{3}$, P Hokkanen ${ }^{1}$, M L Hänninen4, A Kaarna², T Meri ${ }^{5}$, M Kuusi $^{3}$ \\ 1. Food Control Unit, Helsinki City Health Department, Finland \\ 2. Epidemiology Unit, Helsinki City Health Department, Finland \\ 3. National Institute for Health and Welfare, Helsinki, Finland \\ 4. Department of Food and Environmental Hygiene, University of Helsinki, Finland \\ 5. Helsinki University Central Hospital Laboratory HUSLAB, Helsinki, Finland
}

\begin{abstract}
We report the first foodborne outbreak caused by Cryptosporidium parvum in Finland. The outbreak occurred among personnel of the Public Works Department in Helsinki, who had eaten in the same canteen. 72 persons fell ill with diarrhoea, none was hospitalised. Four faecal samples obtained from 12 ill persons were positive for Cryptosporidium by an antigen identification assay and microscopy. The vehicle of infection could not be identified with certainty but a salad mixture was suspected.
\end{abstract}

\section{Introduction}

Cryptosporidium infection is transmitted by the faecal-oral route and results from the ingestion of Cryptosporidium oocysts through the faecally contaminated water or food or through direct personto-person or animal-to-person contact [1]. The infectious dose is low, 10-30 oocysts [2,3]. The reported foodborne outbreaks are not as common as those caused by swimming in water. In the United States, Cryptosporidium is the leading cause of reported recreational water-associated outbreaks $[1,4,5]$.

On 12 November 2008, the Food Control Unit and the Epidemiology Unit of the Helsinki City Health Department were alerted of a gastroenteritis outbreak among the clients of the canteen of Public Works Department. Tens of people had fallen ill within the two weeks since 31 October. The main symptoms were watery diarrhoea, which lasted approximately one week, abdominal pain, fatigue and nausea. All persons affected had eaten at the canteen of the Public Works Department.

\section{Materials and methods}

The canteen of Public Works Department belongs to a large chain of catering services. The daily lunch includes three dishes of warm food, salad buffet and bread. Approximately $100-150$ persons of the total personnel of 400 use daily the services of the canteen.

According to the standard procedures, the Food Control Unit listed the foods served between 22 and 31 October. The number of different foods and drinks served in the canteen was about 30 per day. A retrospective cohort study was carried out among the personnel by the Food Control Unit. A detailed questionnaire on symptoms and consumption of canteen food during the period of 22 to 31 October was e-mailed to all 400 staff members on
18 November. Completed questionnaires were obtained from 127 persons (response rate $32 \%$ ). A case was defined as a person with diarrhoea (at least four loose stools a day) or laboratory-confirmed Cryptosporidium infection during the period from 31 October to 14 November. Associations between food items and illness were assessed by univariate analysis using the chi-squared test.

In late November, the health inspector examined the consignment records of the canteen and found that some salads had not been included in the questionnaires. These included a mixture of lettuce packed of red and green colour by a Swedish company. The salad mixture had been served during two or three days on the week before the beginning of the outbreak. A separate case-control study was carried out on 19 December. In order to find out about the consumption of the salad mixture, 30 cases and 30 controls randomly identified from the cohort study were interviewed by phone. Of the cases 29 , and of the controls 30 replied.

The canteen was inspected on 14 November and 19 samples of foods and spices used between 27 and 31 October were taken. The food samples of the previous week had already been disposed. The food samples were analysed for Escherichia coli, enterococci, Staphylococcus aureus, Campylobacter, yeasts and molds, and later for Cryptosporidium. Some specimens were analysed also for total aerobic bacteria count, Bacillus cereus and Enterobacteriaceae. Two drinking water samples were taken on 11 November and analysed for total number of aerobic microbes, faecal coliforms, Escherichia coli and free and total chlorine, and estimated for colour, taste, odour and appearance as part of the internal quality control. No irregularities in the kitchen conditions, functions of the staff or in complying with internal quality control were found.

Stool samples were taken on 12 to 14 November from 10 ill quests of the canteen and from two ill members of the kitchen staff. The samples were initially tested for Campylobacter, Salmonella, Shigella and Yersinia spp. as well as norovirus. On 17 November, the investigating team requested stool samples to be analysed for Cryptosporidium. The samples were analysed by using Remel's (Lenexa, US) ProSpecTRGiardia/Cryptosporidium and ProSpecTR. Presence of Cryptosporidium was further verified from all positive 
samples by modified Ziehl-Nielsen staining. Faecal DNA samples of three patients were available for PCR analysis [6].

\section{Results}

Seventy-two persons (41 women, 31 men) met the case definition. The mean age was 48 years. The outbreak peaked on 3 to 4 November when 38 cases fell ill (Figure). Two members of the kitchen staff reported diarrhoea with the onset on 3 November. Watery diarrhoea (100\%), fatigue $(85 \%)$, abdominal pain $(76 \%)$, nausea $(69 \%)$ and headache $(61 \%)$ were the most common symptoms. Fever (31\%) and vomiting (21\%) were reported less often and some patients reported arthralgia or myalgia. The epigastric pain was often described as very severe. Two persons had to visit hospital emergency services, but none was hospitalised.

Four stool samples of 12 persons were found positive for Cryptosporidium. None of them belonged to kitchen staff. No other pathogens were found. Control samples taken from the infected persons approximately two weeks later were found negative for Cryptosporidium. In one sample, the amplification of Cryptosporidium-specific PCR product was successful and the sequence had $100 \%$ similarity with the sequence of $C$. parvum.

Food samples were negative for Escherichia coli, Staphylococcus aureus, Bacillus cereus, Salmonella, Campylobacter and enterococci. Methods to analyse Cryptosporidium from food samples have not been built up and validated in Finland, but the salads were examined by using the same method as for stool samples. These results were negative, too. Analyses of drinking water suggested no faecal contamination. The total number of aerobic bacteria was 1 and $0 \mathrm{cfu} / \mathrm{ml}$.

The analysis of the cohort study did not show significant association between any of the foods served and the illness. In the case-control study, the odds ratio for consumption of the salad mixture was 22.5 (95\% Cl 3.5-177.9).

The imported lot of the salad mixture weighted $486 \mathrm{~kg}$ and consisted of two batches. The batches contained salads from Denmark, France, Spain, Italy and Sweden. According to the records, the lot was divided and sold in small quantities to 130 premises in various municipalities all around Finland. The Building

\section{F I G U R E}

Date of onset of symptoms in persons affected by an outbreak of cryptosporidiosis, November 2008, Helsinki, Finland $(n=72)$

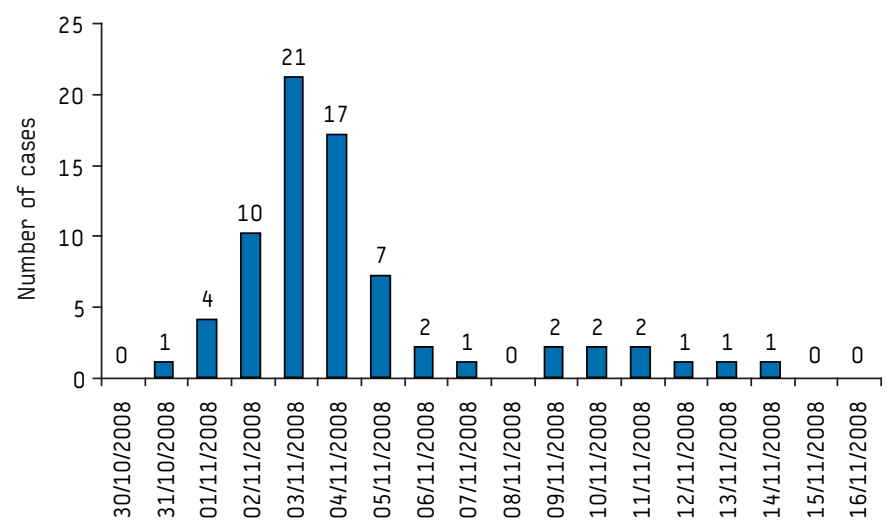

Date of onset of symptoms
Department canteen received $1.5 \mathrm{~kg}$ of the salad mixture possibly originating from both of the batches. Thus, the exact tracing was not possible.

\section{Discussion}

More than 70 guests of a canteen of the Public Works Department of Helsinki fell ill with gastroenteritis in October 2008. The symptoms were compatible with cryptosporidiosis and Cryptosporidium spp. was detected in stool specimens of four patients. Genotyping of one isolate showed that the causative agent was $C$. parvum. A case-control study suggested that mixed salad was the source of the outbreak. This was the first time that Cryptosporidium was found to cause an outbreak in Finland.

All workers of the Public Works Department, personnel of occupational health authorities and the National Public Health Institute were immediately informed about the outbreak. Persons having diarrhoea were instructed about their personal hygiene and were forbidden to use public swimming pools until the end of November. On 21 November, a press release about the outbreak was issued by the local authorities.

Vegetables, and especially salads, have been shown to be an important source of foodborne outbreaks recently $[7,8,9]$. Specifically, Cryptosporidium was linked to consumption of vegetables in Nordic countries [10,11]. In addition, Cryptosporidium was found in samples from fresh produce $[12,13]$. In our outbreak, the vehicle transmitting Cryptosporidium was unfortunately not found. Information about the outbreak came so late to the municipal authorities that relevant food samples were no longer available. Food Control Department of Helsinki recommends that in institutional kitchens, frozen samples of $200 \mathrm{~g}$ from all served foods should be stored for two weeks to enable microbiological investigations after possible outbreaks. Operators of either the producer or the importer of the suspected salad did not comply with the legislation of the European Union. The Article 18 of the Regulation 178/2002 of the European Parliament and of the Council states that the traceability of food or any substance intended to be, or expected to be, incorporated into a food product shall be established at all stages of production, processing and distribution. Food business operators should be able to identify the operators from whom they have been acquiring food and also the ones where food has been delivered to. In addition, the salad finally suspected to be the vehicle, was not included in the initial questionnaire due to an error of the kitchen personnel.

The outbreak described here shows that the public health authorities should be aware of the possibility of foodborne infections caused by protozoa, not only by bacteria and viruses. Testing for Cryptosporidium should be included in the panel of tests performed in gastrointestinal illness and appropriate methods to detect Cryptosporidium in food samples should be developed. It is also imperative that food handlers are aware that proper handling of vegetables is an important method to prevent transmission.

\section{References}

1. Yoder JS, Beach MJ; Centers for Disease Control and Prevention (CDC) Cryptosporidiosis surveillance - United States, 2003-2005. MMWR Surveill Summ. 2007;56(7):1-10.

2. DuPont HL, Chappell CL, Sterling CR, Okhuysen PC, Rose JB, Jakubowski W. The infectivity of Cryptosporidium parvum in healthy volunteers. N Engl J Med. 1995;332(13):855-9. 
3. Okhuysen PC, Chappell CL, Crabb JH, Sterling CR, DuPont HL. Virulence of three distinct Cryptosporidium parvum isolates for healthy adults. J Infect Dis. 1999;180(4):1275-81.

4. Dziuban EJ, Liang JL, Craun GF, Hill V, Yu PA, Painter J, et al. Surveillance for waterborne disease and outbreaks associated with recreational water United States, 2003-2004. MMWR Surveill Summ. 2006;55(12):1-30.

5. Yoder JS, Hlavsa MC, Craun GF, Hill V, Roberts V, Yu PA, et al. Surveillance for waterborne disease and outbreaks associated with recreational water use and other aquatic facility-associated health events - United States, 2005-2006. MMWR Surveill Summ. 2008;57(9):1-29.

6. Spano F, Putignani L, McLauchlin J, Casemore DP, Crisanti A. PCR-RFLP analysis of the Cryptosporidium oocyst wall protein (COWP) gene discriminates between C. wrairi and C. parvum, and between C. parvum isolates of human and animal origin. FEMS Microbiol Lett. 1997;150(2):209-17.

7. Sivapalasingam S, Friedman CR, Cohen L, Tauxe RV. Fresh produce: a growing cause of outbreaks of foodborne illness in the United States, 1973 through 1997. J Food Prot. 2004;67(10):2342-53.

8. Dalton CB, Gregory J, Kirk MD, Stafford RJ, Givney R, Kraa E, Gould D. Foodborne disease outbreaks in Australia, 1995 to 2000. Commun Dis Intell. 2004;28(2):211-24.

9. Long SM, Adak GK, O’Brien SJ, Gillespie IA. General outbreaks of infectious intestinal disease linked with salad vegetables and fruit, England and Wales, 1992-2000. Commun Dis Public Health 2002;5(2):101-5.

10. Ethelberg S, Lisby M, Vestergaard LS, Enemark HL, Olsen KE, Stensvold CR, et al. A foodborne outbreak of Cryptosporidium hominis infection. Epidemiol Infect. 2009;137(3):348-56.

11. Insulander M, de Jong B, Svenungsson B. A food-borne outbreak of cryptosporidiosis among guests and staff at a hotel restaurant in Stockholm county, Sweden, September 2008. Euro Surveill. 2008;13(51):pij=19071. Available from: http://www.eurosurveillance.org/ViewArticle.aspx?ArticleId=19071

12. Robertson LJ, Gjerde B. Occurrence of parasites on fruits and vegetables in Norway. J Food Prot. 2001;64(11):1793-8.

13. Robertson LJ, Johannessen GS, Gjerde BK, Loncarevic S. Microbiological analysis of seed sprouts in Norway. Int J Food Microbiol. 2002;75(1-2):119-26.

This article was published on 16 July 2009.

Citation style for this article: Pönka A, Kotilainen H, Rimhanen-Finne R, Hokkanen P, Hänninen ML, Kaarna A, Meri T, Kuusi M. A foodborne outbreak due to Cryptosporidium parvum in Helsinki, November 2008. Euro Surveill. 2009;14(28):pij=19269. Available online: http://www.eurosurveillance.org/ViewArticle.aspx?ArticleId=19269 